\title{
Elements Of Pharmacy Service And Satisfaction: Patient Versus Consumer?
}

Liliane Bonnal, University of Poitiers, France

Xavier Moinier, University of Poitiers, France

\begin{abstract}
The objective of this paper is to identify the characteristics of what makes retail pharmacies able to guarantee and ensure better customer satisfaction. We have identified the core attributes of retail pharmacies as well as the factors that can contribute to better customer satisfaction in a regulated economic context (pharmacies being in a monopolistic situation regarding the sales of medicines). The aim of this analysis is to check if pharmacies' customers behave as patients or consumers. If the factors linked to the consumption of pharmaceutical products have similar contributions to those noticed for traditional consumer goods (food, clothes and so on), pharmacists will be able to regard their customers as consumers. If it is not the case, the customers will be assimilated to patients, regarding pharmaceutical products as non-traditional consumer goods. The "tetra-class model" (Llosa, 1997) of factors contributing to satisfaction during a pharmacy service experience will serve as the tool for apprehending the role of different pharmacy characteristics in the satisfaction process. We found that French customers seem to behave more as patients than customers in pharmacies. Managerial implications can be deduced. In front of the counter, this research shows that merchandizing at the sales outlet has no effect on the patient's satisfaction. However, it is worth noticing that the self-service area does contribute to consumer satisfaction. Behind the counter, pharmacies' customers behave as patients when purchasing drugs; medecines still remaining a nontraditional product. French customers do not seem ready to purchase medecines from a self-service area. As a result, pharmacy owners can adjust pharmacy service elements to increase the satisfaction level of their customers.
\end{abstract}

Keywords: Elements of Pharmacy; Customer Service; Satisfaction

\section{INTRODUCTION}

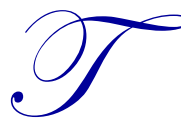

he French pharmacy context is unique in Europe to the extent that pharmaceutical distribution belongs exclusively to pharmacists. The pharmacy outlet is legally defined as "the establishment dedicated to the retail distribution of medicine, products and objects reserved for pharmacists," as well as to the execution of medical or pharmaceutical preparations (Art. L. 5125-1, Public Health Code). So, the client is obliged to use this type of outlet when buying medicine. This obligation no longer holds for those pharmaceutical products that may now be marketed in supermarkets or specialized superstores, the consumer being able to arbitrate between outlet choices. So, in the particular context of the French monopoly of pharmaceutical distribution, pharmacists have long considered the client entering their outlet as a patient and not as a consumer. Pharmacists, protected until now, run the risk of having to adapt to new organizational modes and to the resulting new economic challenges. While pharmacy property is still regulated in France (a pharmacist not being able to own more than two outlets) the possibility for him to invest in several pharmacies seems to be taking shape. If that prospect materializes, the modification will not be without consequence for operating a pharmacy since pharmacists would inevitably have to begin implementing a marketing strategy, not only to attract clients, but also to develop loyalty to their outlet. To do so, pharmacy owners will have to take an interest in customer satisfaction and in the attributes that characterize it. Satisfaction would become henceforth a focal point of the strategy for pharmaceutical outlets since it increases the efficiency of the firm's publicity and communication (Luo \& Homburg, 2007). Because service elements concern the customer's health and well-being (Bolton \& Lemon, 1999), satisfaction at the pharmacy could be a fundamental factor. 
The objective of this research is to identify the attributes of a pharmaceutical outlet that make possible greater the customer satisfaction in a regulated economic context (monopoly applies to the sale of medicine). Client satisfaction is analyzed using the Foscht scale (Foscht et al., 2006). The aim of this analysis is to show if pharmacies' customers behave as patients or consumers. If the factors linked to the consumption of pharmaceutical products have similar contributions to those noticed for traditional consumer goods (food, clothes and so on), pharmacists will be able to regard their customers as consumers. If it is not the case, the customers will be assimilated to patients, regarding pharmaceutical products as nontraditional consumer goods. The value of this study is to deduce the managerial implications that should enable pharmacy owners to define the elements of service which must be adapted to improve the satisfaction of their clients. The "tetra-class model" (Llosa, 1997) of factors contributing to satisfaction during a pharmacy service experience will serve as the tool for apprehending the role of different pharmacy characteristics in the satisfaction process.

\section{CONCEPTUAL FRAMEWORK}

\section{Consumer Satisfaction}

In the case of products exchanged on competitive markets lot of methods exist to conceptualize satisfaction. One approach considers a one-dimensional continuum, opposing two extreme poles (very satisfied versus very unsatisfied): positive and negative (Howard \& Sheth, 1969; Oliver, 1980; Woodruff, Cadotte, \& Jenkin, 1983; Westbrook, 1987). A second approach authors in marketing believe satisfaction to be two-dimensional (Swan \& Combs, 1976; Maddox, 1981; Silvestro \& Johnson 1992; Smith, Weatherly, \& Tansik, 1992), considering that the factors engendering satisfaction are different from those causing dissatisfaction. Finally, a last group of researchers seems to synthesize the two versions by considering satisfaction as one-dimensional while at the same time supposing non-linearity in the function of factors contributing to satisfaction. These non-linear effects have led marketing researchers to investigate the asymmetry of factor impacts on satisfaction and to create plurifactorial models. The idea of this theory is that the contrary of satisfaction is not dissatisfaction but non-satisfaction (Kano, Seraku, Takahashi, \& Tsuji, 1984; Ray \& Gotteland, 2005). Several types of factors can then engender satisfaction (or dissatisfaction).

In the specific context of pharmacy services, satisfaction has been the subject of two studies. Foscht, Angerer, and Moazedi (2006), for Austria, build a scale of satisfaction from elements of pharmacy services. They define 5 factors associated to 20 items (Appendix, Table A1). By a factor analysis they determine the factors which have effect on global satisfaction. This analysis has two limits: it considers responses as continuous variables, the obtained results take into account all the items by only aggregated factors. Our study allows to give more precisely the effect of the elements of pharmacy service on satisfaction. Clerfeuille, Poubanne, Vakrilova, and Petrova (2008, 2009) evaluate the elements of the services provided in Bulgarian pharmacies and their contribution to consumer satisfaction using a tetra-class model. They measure the link between patient satisfaction and loyalty, after pharmaceutical market deregulation and the emergence of private pharmacies in competition to medicine dispensary. Although the situation is different in Bulgaria and in France we compare the results whenever feasible.

\section{Measure of Satisfaction}

Are pharmacy customers patients or consumers? Thanks to pharmacies' consumer satisfaction study, we will be able to verify if the type of products bought (essentially medecines) modifies the evaluation of the services and if the factors linked to the consumption of pharmaceutical products have similar contributions to those noticed for traditional consumer goods (food, clothes and so on). If it is the case, pharmacists will be able to regard their customers as consumers. If it is not the case, the customers will be assimilated to patients, regarding pharmaceutical products as nontraditional consumer goods.

In our study, client satisfaction is analyzed using the Foscht scale (Foscht et al., 2006), which was tested in the context of Austria pharmaceutical distribution with 400 respondents. We questioned those in our sample about satisfaction in general with respect to their pharmacy but also about the service elements in particular (Appendix, Table A1). These elements make possible the conceptualization of a satisfaction process that is as much emotional as cognitive. Its application in the French context required implementing a process of translation, retro-translation 
that many researchers recognize as necessary to assure the comparability of data collected by means of different languages. To measure satisfaction, we choose the D-T scale (Delighted - Terrible, Westbrook, 1980, Appendix, Table A2), which has been used in the framework of research on consumer behavior and has proved to be reliable. We also measure a general appreciation of pharmacy satisfaction on the same scale.

\section{DATA AND RETAINED STATISTICAL MODEL}

\section{Data}

The study is based on a consumer satisfaction survey carried out by electronic mail over 1500 people older than 18 who live in two regions of France. 558 persons from different households responded to the questionnaire. Information concerning patient characteristics (age, sex, number of children, profession), his shopping habits in the outlet (pharmacy client, regularity of visits), and the nature of his purchases (prescription and over-the-courter drugs, personal care and hygiene products or cosmetics) have been collected. The satisfaction criteria proposed by Foscht et al. (2006) thought twenty elements of pharmacy service, regrouped into five categories (Appendix, Table A1), were evaluated, with a scale varying from 1 to 7 (Appendix, Table A3).

The average age of the customer in the sample is 46 (the average age in the French population over 16 for the year 2009 is around 47 years. In the sample, people under 25 and over 60 represent respectively $14.6 \%$ and $13.6 \%$, which is slightly underrepresented in comparison to the national distribution). From the point of view of customer behavior, half the people enter a pharmacy at least once a month. Their presence in the pharmacy is essentially linked to the purchase of medicine prescribed by a doctor, one person out ten never buying nonprescription drugs, and one out of three never buying and personal care and hygiene products or cosmetics.

Regardless of the element under consideration the number of dissatisfied (having checked a score inferior to 4 ) is very low and represents less than $10 \%$. So, on the whole, customers are satisfied (Appendix, Table A3). For all the questions related to satisfaction, the scale employed varies from 1 to 7 . With a score of 4.90 out of 7 , the weakest average registered is for the quality/price ratio element, $9 \%$ declared they were dissatisfied and $27 \%$ were undecided. The highest average registered is for the competence element with a score of 5.94 out of 7, less than $2 \%$ declaring that they were dissatisfied, $8 \%$ being undecided. The average associated with the level of general satisfaction is 5.63. $10 \%$ have an unsettled opinion. On the whole, regardless of the element under consideration the number of dissatisfied (having checked a score inferior to 4) is very low and represents less than $8 \%$ (except for the self-service space, access to shelves and quality/price ratio elements, Appendix, Table A3). Confirmatory factor analysis shows that all the criteria selected for measuring satisfaction can be reduced to a single axis (Foscht et al., 2006), which in our study represents 55\% of the variance (principal component analysis, PCA). All the elements have factor weights greater than 0.5 . To verify the internal coherence of the scale and analyse its reliability, we calculated Cronbach's alphas coefficients. All are greater than 0.9, they demonstrate that the measurement tool thus developed does possess good-quality reliability. The coordinates associated to that axis will then be used to define the profile of the most and least satisfied customers.

\section{The Retained Statistical Model: The Tetra Class Model}

Several methods are available to measure the satisfaction. With her tetra-class model, Llosa (1997) takes into consideration two classes (positive versus negative). In the modeling proposed by Brandt (1988), Mitall, Ross, and Baldasare (1998) or also Brandt and Scharioth (1998), three classes are considered (positive, neuter, negative). However, the small number of dissatisfied respondents - as much for the level of general satisfaction as for the various elements of pharmacy service, see Appendix, Table A3 - hinder the use of techniques capable of measuring satisfaction and dissatisfaction on the basis of three classes. We have therefore selected Llosa's (1997) tetra-class model, which has the advantage of presenting, by means of simple and visual mapping, the weights in general satisfaction of the elements under consideration. In addition, this model possesses an established external validity with regard to various research projects in which it has been used, in the framework of quite varied service activities (Bartikowski \& Llosa, 2004; Merdinger-Rumpler, 2009; Clerfeuille et al., 2008, 2009 for recent applications). 
In the tetra-class model, the contribution of elements to satisfaction is calculated through correspondence factorial analysis (CFA). The modalities of the item general satisfaction and of all the elements capable of influencing satisfaction (obtained in the previous PCA) are reduced to two classes (positive satisfaction/negative satisfaction, which in the context of this study amounts, to positive satisfaction/non-positive satisfaction). The decomposition into two modalities is founded upon the statistical method of segmentation depicted in classification and regression trees (the C\&RT models). This method permits the separation of the scores of each element into two groups that have the greatest power of discrimination, the C\&RT binary segmentation algorithm identifying homogenous subgroups by generating "cut points" in the classification tree (Breiman, Friedman, Olshen, \& Stonce, 1984). Such segmentation makes it possible to obtain two classes whose inter-class variance is maximized and whose intra-class variance is minimized. For most of the 20 elements, the positive modalities were the scores 6 and 7, the negative (non-positive) modalities assuming other values (see Appendix, Table A3). This analysis supposes that a single factorial axis suffices to explain the variance of the set under study. This axis is interpreted as an axis of satisfaction along which figure two modalities of general satisfaction and two modalities for each element (positively and negatively evaluated).

From the CFA, we obtain the coordinates of two modalities for each element. A simple way to represent graphically the results of this analysis is to consider a plane in which points along the abscissa show the contribution of elements to the level of general satisfaction of the client when he considers them negatively and in which points along the ordinate show the contribution of elements to the level of general satisfaction when he considers them positively. The coordinates are normalized using the index of general satisfaction. The normalization makes it possible to establish the frontiers and distinguish the four categories of elements that are defined in the framework of multifactor models. So, services are classified in one of the four categories according to the way in which they affect the client's experiences:

- $\quad$ "Basic" factors contributing to dissatisfaction only when they are considered negatively, but which do not contribute to satisfaction even when evaluated positively,

- "Attractive" or "plus" factors that contribute to satisfaction only when evaluated favorably, but that do not play a role in dissatisfaction,

- "One-dimensional" or "key" factors that contribute to satisfaction when they are favorably evaluated, and which contributed to dissatisfaction when the evaluation is unfavorable,

- "Indifferent" or "secondary" factors that have little or no impact on the level of satisfaction or dissatisfaction.

\section{RESULTS}

Figure 1 allows us to observe that multifactor model may be used with French data to study customer satisfaction in terms of retail pharmacy services and gives the distribution of pharmacy service elements. This conclusion is compatible with the research done on Bulgarian data (Clerfeuille et al., 2008, 2009). There are no "basic" elements.

"Key" factors: competence, personnel friendliness, listening skills and medicine in stock. The "key" elements strongly contribute in all cases to the degree of general satisfaction.

The elements of pharmacy services linked to staff and to pharmacists related to the heart of the pharmacy profession confirm the patient's attachment to the pharmacist's interpersonal skills and knowledge. When the customer goes to the pharmacy, he entrusts his health and well-being to the pharmacy personnel. A relationship of confidence must therefore be established between the two. This relationship can only be durable if the customer is satisfied with service elements.

The pharmaceutical distribution monopoly obligates the pharmacist with respect to the availability and the quality of the drugs. This obligation makes failure of this service quasi-impossible. Nevertheless, it may occur due to stock management problems, or to lack of storage space, that the totality of the prescribed medicine cannot be provided when the client comes into the pharmacy. He is then forced to come a second time. Customers' purchase experience shows this element to be essential, customer won't accept to leave the pharmacy without their medicine. 
These two results are similar to those Foscht et al. (2006) but differ from those of Clerfeuille et al. (2008, 2009), they found "basic" elements.

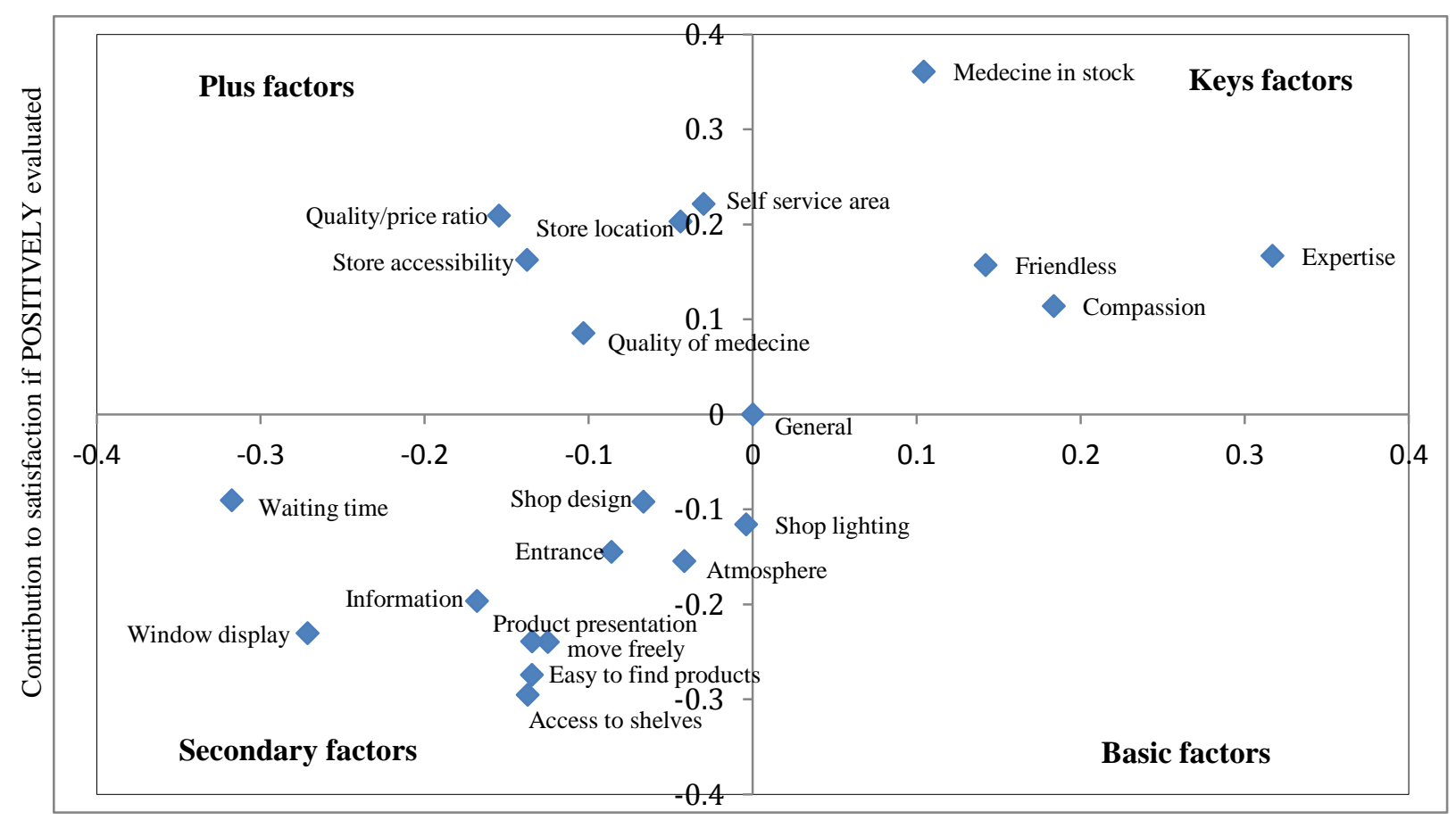

Contribution to satisfaction if NEGATIVELY evaluated

Figure 1: Pharmacy Service Elements Displayed in the Tetra-Class Model

"Plus" factors: pharmacy location, store accessibility, self-service area, medicine quality and quality/price ratio. These items contribute to satisfaction only.

The customers enter a pharmacy to have medicine delivered to them and not to stroll about in a self-service area as in a traditional commercial outlet. This result is comparable to the findings of Foscht et al. (2006).

The quality/price ratio of medicine is found among the "plus" elements. Because in most cases the customer does not pay for the drugs delivered in pharmacies, it is difficult for them to really appreciate this ratio. In Bulgary, pharmacies' customers regard it as "basic." Considering the customer's lack of knowledge and information (medicines are nontraditional goods), this appreciation depends on the medecine's efficiency and its price and has to be taken cautiously. It would explain why medicine quality is also a "plus" element, people would associate quality to the drug efficiency.

Because of French regulations fixing quotas for pharmacy implantations, clients can find a pharmacy near their place of residence or their healthcare center. Access to the store is often facilitated by parking (Foscht et al. (2006) does not show a significant effect).

"Secondary" elements: waiting time, lighting, entrance atmosphere, shop design, freedom of movement in the pharmacy, information, access to products and to shelves, presentation, window display. These items have no impact on satisfaction (neither positive nor negative).

For clothes or food purchase, for example, the atmosphere in the sales outlet may have more importance that the product itself (Kotler, 1973), it is considered as a "basic" element (dissatisfaction of an item has a negative impact on global satisfaction and satisfaction of an item has a positive impact on global satisfaction). In Clerfeuille et al. $(2008,2009)$ atmosphere is a "basic" element. Foscht et al. (2006) found that the first impression elements are "keys." 
In this study the atmosphere is characterized by two types of factors. The first type is related to product presentation, which is to say: to the deliberate conception of space inside the pharmacy itself (access to products and to shelves, lighting, freedom of movement in the pharmacy, ...) for the purpose of producing certain effects on the people. The second type is linked to the conception of the pharmacy's exterior, put otherwise: to the first impression (entrance atmosphere, shop design, window display ...). Because in France the pharmacist has "public service missions" and must "guarantee the respect for the requirement of public health and consumer protection," pharmacies are not considered to be commercial outlets. Clients go to the pharmacy essentially for medical reasons and are not very interested in the layout and atmosphere of the pharmacy, unlike consumers. This finding truly raises questions concerning the managerial practices and organizational preferences of pharmacists, notably of those belonging to pharmacist groups, who make use of these service elements to compare favorably with their competitors.

Waiting time does not enter the client's satisfaction or dissatisfaction. The delivery of medicine is traditionally not done in urgency, and it seems normal that the practitioner take his time for pharmaceutical counseling. This waiting time seems to be integrated in the client's consumption experience and does not belong to his high-priority pharmacy service elements. It should be noted that some pharmacy outlets attempt to develop counters for pharmaceutical consultations within the pharmacy, which will increase the customer's waiting time. This result is similar to those of Foscht et al. (2006) but for Clerfeuille et al. $(2008,2009)$ time waiting is "basic."

\section{DISCUSSION, IMPLICATIONS, LIMITS AND DIRECTIONS OF RESEARCH}

\section{Discussion: Are Customers Patients or Consumers?}

Do pharmacies' customers behave as patients or consumers? A response can be given by comparing our results with those obtained for different purchase contexts, types of goods purchased and types of retail outlets (Table 1).

Table 1: Classification of Items Based on Store Visits

\begin{tabular}{|c|c|c|c|c|c|}
\hline \multirow[t]{2}{*}{ Elements } & \multicolumn{3}{|c|}{ Pharmacies } & \multirow{2}{*}{$\begin{array}{c}\text { Hypermarket } \\
\text { Goods }^{(1)}\end{array}$} & \multirow{2}{*}{$\begin{array}{c}\text { Restaurant } \\
\text { Services }^{(1),(2)}\end{array}$} \\
\hline & Bonnal Moinier & Foscht et al. & Clerfeuille et al. & & \\
\hline Window display & secondary & key & basic & key & secondary \\
\hline Shop lighting & Secondary & secondary & basic & basic & secondary \\
\hline Access to shelves & secondary & secondary & basic & Basic & \\
\hline Friendliness & key & key & basic & secondary & secondary \\
\hline Expertise & key & key & basic & secondary & secondary \\
\hline Compassion & key & key & basic & secondary & secondary \\
\hline Product in stock & key & key & basic & basic & basic \\
\hline Quality of product & plus & key & basic & & \\
\hline Waiting time & secondary & secondary & basic & key & key \\
\hline Quality/price ratio & plus & key & basic & basic & key \\
\hline Store location & plus & secondary & secondary & secondary & key \\
\hline Store accessibility & plus & secondary & secondary & secondary & secondary \\
\hline
\end{tabular}

Lecture: basic and plus cannot be obtained in Foscht et al. analysis (2006). (1): Llosa (1997), (2) Mouette (2005). Only comparable items have been considered.

Although our items' ranking cannot be directly compared to Foscht's et al. (2006) we can still notice a relative resemblance between the results obtained except for four elements? Indeed, the window display and waiting time items do not have the same effect. In Foscht et al.'s study, these results are included within a set of elements. If they were considered separately, the effects might be different. The main difference between the two studies lies in the location and accessibility of pharmacies. These elements are ranked as positive for us but have no effect for Foscht et al. Differences in location strategies and networks could account for that difference. However, as was the case before, our results are very different from those obtained by Clerfeuille et al. French and Bulgarian customers seem to have different buying behaviours that we tried to explain earlier on. 
Let us now compare our results with the results obtained for basic consumer goods (Table 2). The first impression elements (Appendix, Table A1) have been ranked similarly for pharmacies and restaurants. Pharmacies' customers seem to behave like service consumers. As for the other elements, the ranking is different. Regarding consumer goods, the items linked to the staff are "secondary" (items have little impact on the level of satisfaction) there are "keys" (factors contribute to the satisfaction and also to the dissatisfaction) for pharmacies. Stock is also very important for customers' pharmacy while there has no impact for "normal" goods (clothes, food ...) or services.

The waiting time item does not count for French pharmacies' customers ("secondary" factor) but it does ("basic" factor) for Bulgarian pharmacies' customers. As French customers behave more as patients than as consumers, they probably consider waiting as something both normal and necessary. Undeniably, the perception of that waiting time in a French pharmacy cannot be evaluated in the same way as the waiting time in restaurants and hypermarkets that customers regard as a "key" element. We may accept to have to wait in a pharmacy but it also seems logical to be more sensitive to the time spent waiting when being served in a restaurant (pleasure time) or when doing shopping in a hypermarket (time lost). As for the quality/price element, the results obtained are also quite disimilar: considered as "plus" for French pharmacies customers, "basic" for Bulgarian pharmacies' customers and "key" for consumers of services (as in restaurants). In the case of the satisfaction study carried out among restaurants, the appreciation is of course more simple to carry out, which easily explains why this element is "key." Consumers can easily evaluate the quality of the meal and service compared to the price paid. This element is considered as basic for hypermarkets' customers since they expect a good quality/price ratio from the basic consumer goods they buy. If it is not the case, this factor negatively weighs on consumer satisfaction.

In France, pharmacies' customers seem to behave more specifically as patients than as customers. We can notice that Bulgarians satisfaction towards pharmacy is close to that of consumers towards goods (hypermarkets). Bulgarians seems to consider product of pharmacy as "normal" goods.

\section{Implications}

This analysis of pharmacy satisfaction leads to important managerial implications for practitioners on two levels. First of all in the short run, it enables the pharmacist to define his managerial actions more clearly. In front of the counter, the issue is to propose the pharmacy's offer, placing it within the customer's reach without restriction. Our research shows that merchandizing at the sales outlet has no effect on the patient's satisfaction. This finding raises questions about pharmacy managerial practices and operational choices of pharmacies particularly for pharmacists who are developing pharmacy sales points modeled on the classic commercial outlet. However, it is worth noticing that the self-service area does contribute to the consumer's satisfaction. This element constitutes a promising lever of attraction for the future due to the over-the-counter, given the number of pharmaceutical drugs freely accessible in the self-service area.

Behind the counter, we are dealing with the service elements inherent to the pharmacist's profession. Beyond the managerial preoccupations underlying the evolution of pharmaceutical distribution, the pharmacist can see that his role has been strengthened with respect to services contributing to patient satisfaction. Pharmacies' customers are patients when purchasing drugs, medecines still remain a nontraditional product. The asymmetric information between pharmacists and patients requires the presence of an expert. Even if they are receptive to the self-service area, French customers do not seem ready to purchase self-service medicines. This leads to the question of developing the opportunity that a self medication shelf would represent.

In the medium term, if the situation of market monopoly in which pharmacists find themselves were to disappear, it may be imagined that pharmacy owners would implement commercial policies that are closer to those observed in classic commercial markets. As for the medicine delivered on prescription, competition will not be on pricing but rather on "key" services. For personal care and hygiene products and cosmetics, non-prescription and/or self-service drugs, competition may in addition take place through pricing. Commercial and managerial policies will have to be modified and adjusted in accordance with the service elements of satisfaction defined by the model. 


\section{Limits and Directions of Research}

Our research presents few limits. We consider that customers were homogenous. Yet, client expectations may not be the same depending on the reason of their presence in the pharmacy, their age or the area where they live. So, segmented analyses in terms of these three elements could be done.

In addition, we did not distinguish in the analysis the organizational mode of the pharmacy. Indeed, while pharmacists are traditionally "independent," some of them have joined pharmacy groupings, which are groups of pharmacists who are financially unconnected owners of the license (the pharmacist is owner of one or two pharmacies, see Moinier, 2009). In this way, the pharmacy grouping assures their outlet members benefit from the network's own merchandizing, integrating a whole set of specific services. It would be interesting to compare the customer's satisfaction according to whether or not the pharmacy patronized belongs to a pharmacy operating under a group of pharmacists. Indeed, are the service elements still classed as "secondary" by the pharmacies working in a group that pays particular attention to the outlay and atmosphere of the sales outlet?

Furthermore, we have not accounted for the customer relationship that plays a role in the consumer's overall satisfaction (Garborino \& Johnson, 1999) although the patient does seem to attach great importance to the relationship with the pharmacy's owner. Loyalty to a sales outlet would seem to be the objective for pharmacists to attain. The relation between satisfaction and loyalty could be explained by consumer commitment and confidence (Morgan \& Hunt, 1994; Macintosh \& Lockshin, 1997).

\section{AUTHOR INFORMATION}

Liliane Bonnal, $\mathrm{PhD}$, is a Professor of Economics at the University of Poitiers, France. Her research focuses generally on applied economics with a particular focus on econometric and statistic methods. She is a research associate at the Toulouse School of Economics, France. She has published numerous articles in outlets such as Applied Economics, Applied Economics letters, International Journal of Manpower and Economies Of Innovation and New Technology. E-mail: liliane.bonnal@univ-poitiers.fr (Corresponding author)

Xavier Moinier, $\mathrm{PhD}$, is an Associate Professor of Marketing at the University of Poitiers, France. His research focuses generally on health marketing with a particular focus on retail pharmacy. He is the author of "Marketing Strategy of Pharmacy Business" published by Estem. He is a reviewer for two journals: World Marketing Congress of Academy of Marketing Science and International Marketing. E-mail: xavier.moinier@univ-poitiers.fr

\section{REFERENCES}

1. Bartikowski, B., \& Llosa, S. (2004). Customer satisfaction measurement: Comparing four methods of attribute categorizations. Service Industries Journal, 24(4), 67-82.

2. Brandt, R. D. (1988). How service marketers can identify value-enhancing service elements. The Journal of Services Marketing, 2(3), 35-41.

3. Brandt, R. D., \& Scharioth, J. (1998). Attribute life cycle analysis - alternatives to the Kano method. Proceedings of the 51st Annual Esomar conference.

4. Breiman, L., Friedman, J. H., Olshen, R. A., \& Stonce, C. J. (1984). Classification and regression trees. Belmont, California: Wadsworth.

5. Bolton, R. N., \& Lemon, K. N. (1999). A dynamic model of customer's usage of services: usage as an antecedent and consequence of satisfaction. Journal of Marketing Research, 36(2), 171-186.

6. Clerfeuille, F., Poubanne, Y., Vakrilova, M., \& Petrova, G. (2008). Evaluation of the consumer's satisfaction: An application to the Bulgarian Pharmacies. Research in Social and Administrative Pharmacy, 4(3), 258-271.

7. Clerfeuille, F., Poubanne, Y., Vakrilova, M., \& Petrova, G. (2009). The applicability of the Tetraclass Model to the management of the patient satisfaction in the pharmacies. Journal of Pharmacy Practice, 7(1), 19-28.

8. Foscht, T., Angerer, T., \& Moazedi, L. (2006). Customer satisfaction and the Austrian pharmacy retailing industry seen from growth - oriented perspective. European Retail Digest, 50, 31-36. 
9. Garborino, E., \& Johnson, M. S. (1999). The different roles of satisfaction, trust, and commitment in Customer relationships. Journal of Marketing, 63(2), 70-87.

10. Howard, J. A., \& Sheth, J. N. S. (1969). The theory of buyer behaviour. New York: John Wiley.

11. Kano, N., Seraku, N., Takahashi, F., \& Tsuji, S. (1984). Attractive quality and must-be quality. The best of quality, 7, 165-186.

12. Kotler, P. (1973). Atmospherics as a marketing tool. Journal of Retailing, 49(4), 48-64.

13. Llosa, S. (1997). L’analyse de la contribution des éléments de service à la satisfaction: Un modèle Tetraclasse. Décisions Marketing, 10, 81-88.

14. Luo, X., \& Homburg, C. (2007). Neglected outcomes of customer satisfaction. Journal of Marketing, 71, 133-149.

15. Macintosh, G., \& Lockshin, L. S. (1997). Retail relationships and store loyalty: A multilevel perspective. International Journal of Research in Marketing, 14(5), 487-497.

16. Maddox, R. N. (1981). Two factors theory and consumer satisfaction: Replication and extension. Journal of Consumer Research, 8(1), 97-102.

17. Merdinger-Rumpler, C. (2009). Contribution des éléments de service à la satisfaction du patient hospitalisé: Une application du modèle tétraclasse. Décisions Marketing, 53, 43-52.

18. Mitall, V., Ross, W. T., \& Baldasare, P. M. (1998). The asymmetric impact of negative and positive attribute-level performance on overall satisfaction and repurchase intentions. Journal of Marketing, 62(1), 33-47.

19. Moinier, X. (2009). L’enseigne de pharmaciens: Une spécificité au cœur de la distribution. Décisions Marketing, 53, 7-17.

20. Morgan, R. M., \& Hunt, S. D. (1994). The commitment trust theory of relationship marketing. Journal of Marketing, 63(3), 88-101.

21. Mouette, J. Stabilité du modèle tétra-classe dans le cadre d'une analyse par segment. WP CEROG nº702.

22. Oliver, R. L. (1980). A cognitive model of the antecedents and consequences of satisfaction decisions. Journal of Marketing Research, 17(4), 460-469.

23. Ray, D., \& Gotteland D. (2005). Mesurer l'asymétrie des impacts des facteurs de satisfaction: Proposition d'une nouvelle méthode, Proceedings of the XXI International AFM Research Seminar, Nancy, France.

24. Silvestro, R., \& Johnson, R. (1992). The determinants of service quality: Hygiene and enhancing factors, Quality in services conferences. New York: The Business Research Institute at John's University.

25. Swan, J. E., \& Combs, L. J. (1976). Product performance and consumer satisfaction: A new concept. Journal of Marketing, 40(2), 25-33.

26. Westbrook, R. A. (1980). Interpersonal affective influences on consumer satisfaction with products. Journal of Marketing Research, 7, 49-54.

27. Westbrook, R. A. (1987). Product/consumption-based affective responses and post purchase processes. Journal of Marketing Research, 24(3), 258-270.

28. Woodruff, R. B., Cadotte, E. B., \& Jenkins, R. L. (1983). Modeling consumer satisfaction processes using experience-based norms. Journal of Marketing Research, 20(3), 296-304. 


\section{APPENDIX}

Table A1: List of Factors and Items (Foscht et al., 2006)

\begin{tabular}{ccccc}
\hline First Impression & Presentation of Products & Staff And Pharmacist & Quality/Price Ratio & Location \\
\hline Shop design & Possibility to move freely & & & \\
Window display & Easy to find products & Friendliness & Medicine in stock & Quality of medicine \\
Shop lighting & Access to shelves & Expertise & Store location \\
Entrance & Self-service area & Compassion & Quality/price ratio & Store accessibility \\
Atmosphere & Product presentation & & \\
Information & & & \\
\hline
\end{tabular}

Table A2: Delighted - Terrible Scale

"How do you feel about your life as a whole.....?" 7

delighted
6

pleased
5

mostly satisfied
4

mixed
3

mostly dissatisfied
2

unhappy
1

terrible

Table A3: Elements of General Satisfaction and Descriptive Statistics Associated with the Different Elements in the Satisfaction Scale

\begin{tabular}{|c|c|c|c|c|c|c|c|}
\hline \multirow[t]{2}{*}{ Service Element } & \multirow[t]{2}{*}{ Mean } & \multirow{2}{*}{$\begin{array}{l}\text { Standard } \\
\text { Deviation }\end{array}$} & \multirow[t]{2}{*}{ Minimum } & \multirow[t]{2}{*}{ Maximum } & \multirow[t]{2}{*}{ C\&RT* } & \multicolumn{2}{|c|}{$\begin{array}{c}\text { Proportion of Scores } \\
(\text { In \%) }\end{array}$} \\
\hline & & & & & & 1-3 & 4 \\
\hline General satisfaction & 5.6 & 1.0 & 1 & 7 & $6-7$ & 1.3 & 9.7 \\
\hline Shop design & 4.6 & 1.1 & 2 & 7 & $6-7$ & 2.7 & 12.4 \\
\hline Window display & 5.1 & 1.1 & 1 & 7 & $6-7$ & 4.5 & 29.6 \\
\hline Shop lighting & 5.5 & 1.0 & 2 & 7 & $6-7$ & 1.1 & 13.8 \\
\hline Entrance & 5.4 & 1.1 & 2 & 7 & $6-7$ & 3.0 & 18.1 \\
\hline Atmosphere & 5.4 & 1.1 & 1 & 7 & $6-7$ & 3.4 & 14.5 \\
\hline Information & 5.2 & 1.2 & 1 & 7 & $6-7$ & 7.0 & 17.0 \\
\hline Possibility to move freely & 5.3 & 1.2 & 1 & 7 & $6-7$ & 7.5 & 16.7 \\
\hline Easy to find products & 5.2 & 1.2 & 1 & 7 & $6-7$ & 5.6 & 19.5 \\
\hline Access to shelves & 5.2 & 1.1 & 1 & 7 & $6-7$ & 6.3 & 21.7 \\
\hline Self-service area & 5.1 & 1.2 & 1 & 7 & $5-6-7$ & 9.1 & 22.0 \\
\hline Product presentation & 5.3 & 1.1 & 1 & 7 & $6-7$ & 4.7 & 17.6 \\
\hline Friendliness & 5.9 & 1.1 & 1 & 7 & $6-7$ & 3.2 & 7.7 \\
\hline Expertise & 5.9 & 1.1 & 1 & 7 & $6-7$ & 2.9 & 6.8 \\
\hline Compassion & 5.9 & 1.1 & 1 & 7 & $6-7$ & 3.4 & 7.2 \\
\hline Medicine in stock & 5.4 & 1.1 & 1 & 7 & $5-6-7$ & 5.6 & 12.5 \\
\hline Quality of medicine & 5.6 & 1.0 & 1 & 7 & $6-7$ & 1.6 & 13.6 \\
\hline Waiting time & 5.1 & 1.1 & 1 & 7 & $6-7$ & 8.6 & 16.7 \\
\hline Quality/price ratio & 4.9 & 1.2 & 1 & 7 & $5-6-7$ & 9.3 & 26.9 \\
\hline Store location & 5.8 & 1.5 & 1 & 7 & $6-7$ & 2.7 & 8.2 \\
\hline Store accessibility & 5.7 & 1.2 & 1 & 7 & $6-7$ & 4.8 & 10.0 \\
\hline
\end{tabular}

* Modalities characterizing positive satisfaction, grouped according to the classification. 